\title{
Meslek Liselerinde Çalışan Öğretmenlerin Örgüt Kültürü ve Değişime İlişkin Görüşlerinin İncelenmesi ${ }^{1 *}$
}

\author{
Ŭ̆ur ÖZALP \\ Doktora Öğrencisi, Marmara Üniversitesi, \\ Eğitim Bilimleri Enstitüsü, Eğitim Bilimleri Ana Bilim Dalı, \\ Eğitim Yönetimi ve Denetimi Bilim Dalı \\ ozalp.ugur@gmail.com \\ Orcid ID: https://orcid.org/0000-0001-6790-5304

\section{Münevver ÇETIN} \\ Prof. Dr., Marmara Üniversitesi, \\ Eğitim Bilimleri Enstitüsü, Eğitim Bilimleri Ana Bilim Dalı, \\ Eğitim Yönetimi ve Denetimi Bilim Dalı \\ munevverolcum@gmail.com \\ Orcid ID: https://orcid.org/0000-0002-1203-9098
}

\section{$\ddot{O ̈ z}$}

$\mathrm{Bu}$ araştırmanın temel amacı, mesleki ve teknik eğitim veren ortaöğretim kurumlarında görev yapan öğretmenlerin örgüt kültürüne ve değişime ilişkin görüşlerini incelemektir. Olgu bilim deseninde tasarlanmış bu nitel çalışmada veriler yarı yapılandırılmış görüşme formu aracıllı̆̆yla toplanmıştır. Araştırmanın çalışma grubunu, 2017-2018 eğitim-öğretim y1lında İstanbul ilindeki meslekî ve teknik liselerde çalışmakta olan 18 öğretmen oluşturmaktadır.

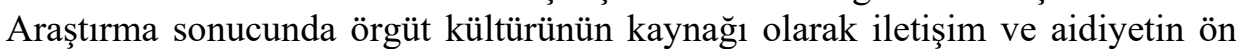
plana çıktığ1 görülürken örgüt kültüründe öncelikli olarak değişime gidilmesi gereken alanların başında iletişim ve karara katılımın geldiği görülmektedir. Bunlarla birlikte, örgüt kültürünün değișiminin önündeki başlıca engellerin değişime karş1 çıkma ve örgüt üyelerinin alışkanlıklarından vaz geçmemesi olduğu sonuçlarına ulaşılmıştır.

Anahtar Kelimeler: Örgüt kültürü, Örgütsel Değişim, Meslek Lisesi, Mesleki ve Teknik Eğitim.

\footnotetext{
${ }^{1}$ Makale Geliş/Kabul Tarihi: 14.02.2019 / 19.04.2021

* 13-15 Eylül 2018 tarihleri arasında gerçekleştirilen II. Uluslararası Eğitim Araştırmaları ve Öğretmen Eğitimi Kongresinde sunulan sözlü bildirinin genişletilmiş halidir.

Künye Bilgisi: Özalp, U. ve Çetin, M. (2021). Meslek liselerinde çalışan öğretmenlerin örgüt kültürü ve değişime iliş̧in görüşlerinin incelenmesi. Kahramanmaraş Sütçü Imam Üniversitesi Sosyal Bilimler Dergisi, 18(1), 131-157. DOI: 10.33437/ksusbd.526949
} 


\title{
Examining the Opinions of Teachers Working in Vocational High Schools on Organizational Culture and Change
}

\begin{abstract}
The main purpose of this research is to examine the opinions of teachers working in secondary education institutions providing vocational and technical education, on organizational culture and change. In this qualitative study, which is in phenomenology design, data was collected through a semi-structured interview form. The study group consisted of 18 teachers working in vocational and technical high schools in İstanbul during the 2017-2018 academic year. Depending on the results it was revealed that while communication and belonging were seen as prominent sources of organizational culture, communication and participation in decision making were seen as the primary areas that need to be changed in organizational culture. In addition, it was concluded that the main obstacles to the change of organizational culture are opposing to change and members' not leaving their habits.
\end{abstract}

Keywords: Organizational Culture, Organizational Change, Vocational High School, Vocational And Technical Education.

\section{GİRIŞ}

Kültür, örgütün tüm boyutları içerisinde önemli bir yere sahiptir. Kültürün arka planda kaldığı örgütler dahi üyelerinin düşünüş biçimleri, değer yargıları ve eylemleri ile üyelerinin sahip olduğu ortak kültürel ve sosyal değerlerin yönlendirici etkisi altındadır (Alvesson, 2002: 1). Örgüt üyelerinin bireysel olarak sahip olduğu bu sosyal ve kültürel değerlerin etkisi altında olan örgüt kültürü, örgütün hem üyeleri hem de üyeleri dışında kalan diğer paydaşlarıyla olan etkileşimini de kaçınılmaz olarak etkilemektedir (Hatch ve Schultz, 2007: 360). Dolayısıyla kültürün, iş yerindeki her bir etkileşim üzerine etkisi olduğu dile getirilebilir. $\mathrm{Bu}$ bakımdan, insan etkileşimleri, bir örgütün rekabet edebilirliğini belirlemede en önemli unsur olduğu ifade edilebilir. Örgüt içerisindeki kararlar, örgüt üyelerinin etkileşimlerine dayanarak alınır (Reisyan, 2016: 13).

Kültür kelimesinin izi antik Roma'ya kadar sürülebilir, ancak kavramın üzerinde fikir birliğine varılmış bir tanımı bulunmamaktadır (Reisyan, 2016: 21). Paylaşılan yaşantının yazılı olmayan kuralları kültür olarak adlandırılmaktadır. Kültür, üyesi bulunulan sosyal grubu diğer gruplardan ayıran zihinsel yazılımın adıdır. Kültür, paylaşılan bir sosyal ortamda ortaya çıkmakta ve bu ortama sonradan dahil olanlar tarafından öğrenilmektedir. Dolayısıyla kültür kolektif bir 
yaşantının ürünüdür. Bireyler, yaşantılarının farklı aşamalarında çoğunlukla eş zamanlı olarak farklı sosyal gruplar içerisinde yer aldığından kültürün dahil olunan gruba göre farklı katmanlardan oluştuğu ifade edilebilir (Hofstede vd., 2010: 6; Schein, 2011: xi). Kültür, başkalarıyla olan etkileşimlerimiz neticesinde sürekli olarak yeniden oluşturulur ve kendi davranışlarımız tarafından şekillendirilir. Bir grubun kültürü, geçerliliğgi kabul edilmiş, grubun yeni üyelerine algılama, düşünme ve hissetme açısından doğru yol olarak öğretilen, grubun karşılaştığı dışa uyum ve iç bütünleşmeye ilişkin sorunları çözdükçe öğrendiği paylaşılan temel varsayımlara ilişkin şablonlardır (Schein, 2010:3-18).

Kültüre ilişkin şu yedi ortak özellikten bahsedilebilir (Alvesson ve Sveningson, 2016: 41):

1. Kültür, bütüncüldür ve bireylere indirgenemeyecek bir olgudur. Kültür, çok sayıda bireyin işin içerisinde olmasını gerektirir.

2. Kültürün tarihsel bir yanı vardır. Kültür gelişen bir olgudur ve gelenekler vasitasıyla aktarılır.

3. Kültür durağandır ve değiştirilmesi zordur. İnsanlar, fikirlerine, değerlerine ve geleneklerine bağlı kalmaya meyillidir.

4. Kültür, sosyal olarak inşa edilen bir olgudur. Kültür, insan ürünüdür ve farklı gruplara aidiyeti olan insanlar tarafından paylaşlır. Farklı gruplar farklı kültürler oluşturur, dolayısıyla, kültürü dayatan insanın doğası değildir.

5. Kültür, hassas, muğlak ve yakalanması zordur. Aslında nitelikseldir ve ölçülüp sınıflandırılması kolay değildir.

6. Kültürü özelliklerini belirtmek için efsane, tören, semboller ve benzer antropolojik terimler kullanılır.

7. En yaygın haliyle kültür, örgütün somut, nesnel ve gözlemlenebilen boyutundan çok düşünme biçimi, değer ve fikirleri ifade eder.

Kültürün, bütüncül ve bireylere indirgenemeyecek bir olgu olması, kültürün bir bağlam içerisinde ele alınması gerektiğine işaret etmektedir (Alvesson ve Sveningson, 2016: 41; Schein, 2010: 87). Örgüt kültürü, örgüt üyelerinin birbirleriyle ve örgüt dışındaki insanlarla etkileşimini kontrol eden, örgüt içerisinde paylaşılan değerler ve normları ifade etmektedir (Jones, 2013: 201). Örgüt kültürü, örgüt üyelerinde bireysel olarak var olmanın ötesinde, tecrübelerin yanında hikayeler ve törenlerle de yeni üyelere aktarılan, paylaşılan inançlar, ideolojiler ve değerlerdir (Ehrhat vd., 2014: 2). 
Jones'a göre (2013: 212) örgüt kültürünün dört kaynăğ vardır. Bu kaynaklar, Şekil 1'de gösterilmiştir.

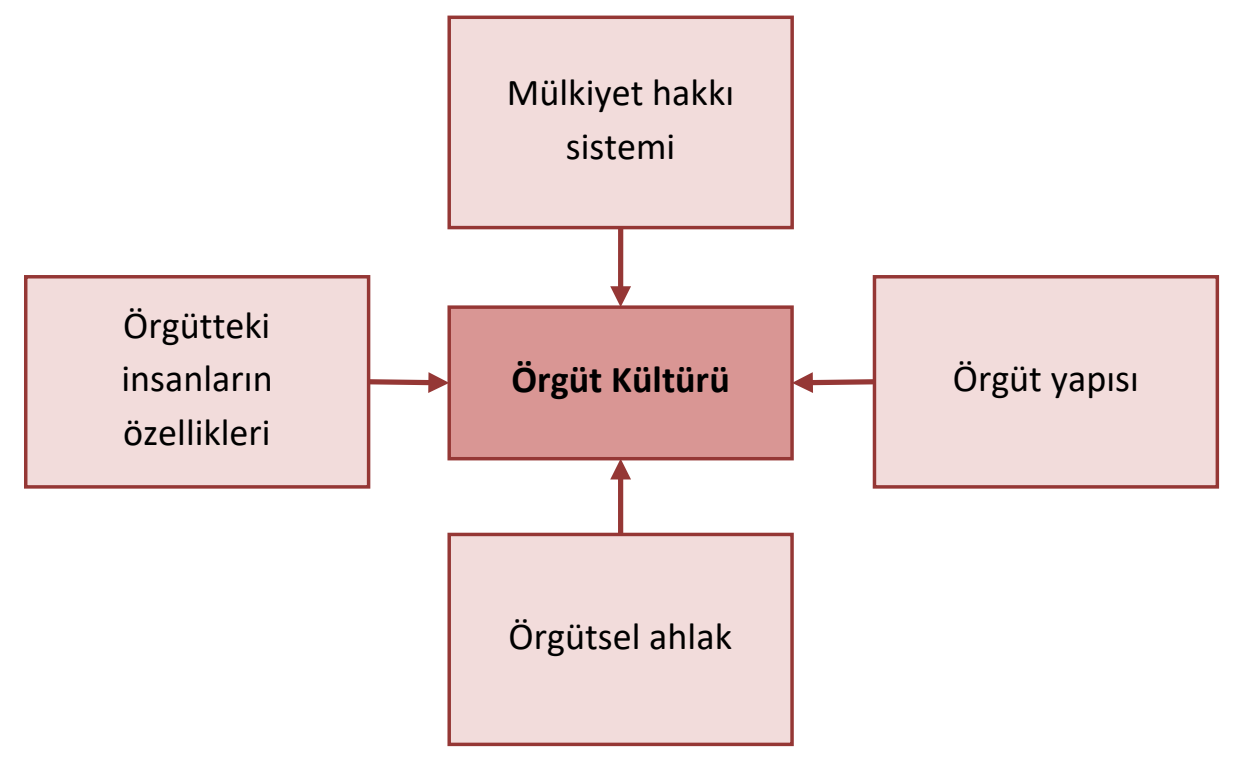

Şekil 1. Örgüt Kültürünün Kaynakları

(Kaynak: Jones, 2013: 212)

Şekil 1 incelendiğinde, mülkiyet hakkının, örgüt yapısının, örgütsel ahlakın ve örgütteki insanların özelliklerinin örgüt kültürünün kaynaklarını oluşturduğu görülmektedir.

Örgütler, sundukları mülkiyet hakkı ile sosyal normların oluşturulmasını sağlar. Örgüt üyelerinin mülkiyet haklarına ilişkin yap1, örgüt kültürünün çeşitlilik göstermesine yol açar (Indacochea vd., 2018: 50; Scholz, 1987: 81).

Örgüt yapıs1, örgütteki görev ve otorite arasındaki ilişkiyi kontrol etmek için kurulan formal sistemdir. Örgüt yapısı, profesyonel etkileşim, iletişim, ortak karar verme ve politika oluşturmada önem taşımaktadır. Örgüt yapısı, süreçlerin ve kişiler arası ilişkilerin yöneticiler tarafından nasıl algılandığını ortaya koyar. Farklı yapılar farklı kültürler ortaya çıkaracağından, yöneticilerin belirli bir örgüt kültürü oluşturmak için belirli bir örgüt yapısı oluşturmaları gerekmektedir. Örneğin, mekanik yapılar ve organik yapılar farklı kültürel değerlerin ortaya çıkmasına yol açar (Jones, 2013: 218; Kimonen vd., 2017: 247; Robles ve Nuqui, 2015: 79). 
Örgüt ahlak1, örgütün paydaşlarıyla ve örgüt içerisindekilerle ilişkilerinde kullandığı ahlakî değerler, inançlar ve kurallardır. Örgüt ahlakı, örgüt üyelerinin bireysel algılarını ve davranış biçimlerini de etkiler. Birçok kültürel değer, örgütün kurucusunun ya da üst yöneticilerinin kişiliği ve inançlarına göre şekillenmektedir ve bunlar örgütün kontrol edemeyeceği değişkenlerdir (Jones, 2013: 213; MacLean vd., 2015: 352).

Örgüt üyelerinin özellikleri, örgüt üyelerinin kişiliği, bilgi düzeyi, becerileri, yaklaşım çeşitleri ve yaratıcılık gibi özelliklerine atfen kullanılır (Shin ve Eom, 2014: 91-93). Örgüt üyelerinin özellikleri, örgüt kültürünün en önemli kaynağının örgütü oluşturan bireyler olmasından dolayı önem taşımaktadır. Farklı örgütler tamamen farklı kültürler geliştirir çünkü farklı değerleri, kişilikleri ve ahlak anlayışları olan bireyleri cezbeder, seçer ve örgüte dahil eder (Jones, 2013: 211-212).

Değişim kaçınılmazdır. Değişimin karmaşıklığını ve değişimi yönetme tekniklerini anlamak bireylere ve örgütlere, belirsiz olan gelecekte karşılaşmaları olas1 güçlüklerle başa çıkma olanağ1 sunar (Gilley vd., 2009: 370). Örgüt kültürünün değiştirilmesi her ne kadar çok zor olsa da imkansız değildir (Burke, 2014: 457).

Gilley vd. (2001) örgütsel değişimi birinci derece değişim ve ikinci derece değişim olmak üzere ikiye ayırmaktadır. Birinci derece değişim, örgütte ortaya çıkan değişimlerin büyük bir bölümü rutinler, etkinlikler, sorunlar ve belirli durumlarla ilgilenmektedir. Örgütte doğal olarak ortaya çıkan ve çalışanların gelişmesini sağlayan küçük gelişmeler ve düzenlemelerdir. Çalışanların doğal gelişimini sağlamak açısından dikkat edilmesi gereken değişkenlerdir. Organize edilmiş bir müdahalenin gerekliliğini zorunlu kılmaz. İkinci derece değişim, liderlerin örgütün temel varsayımlarını sorguladığı ve iş ortamı ve kültürüne ilişkin bilinmeyen yeni unsurları işaret ettiği önemli dönüşümleri hedeflemektedir. Örgüt kültürünün, ana süreçlerinin (yapı, yönetim, karar verme ve performans yönetim sistemi gibi), vizyonunun, misyonunun, değerlerinin, hedeflerinin ve stratejilerinin kapsamlı bir biçimde gözden geçirilmesini kapsayan bu değişim türüne dönüşümcü değişim adı da verilir. Örgüte ayrıntılarıyla yerleştirilen ve örgütün temel doğasını değiştiren değişimlerdir (Gilley vd., 2001: 23).

Örgütsel değişimi tetikleyen iç ve dış güçler vardır. Çoğu durumda örgütsel değişim dış değişimlerin sonucu olarak ortaya çıkar. Örgütsel değişimi tetikleyen dış güçler şunlardır (Alvesson ve Sveningson, 2016: 15):

- Politika,

- Teknoloji, 
- Kültür,

- Demografi,

- Ekonomi,

- Pazara ilişskin değişimler.

Jones (2013: 297) bunlara ek olarak şunları değişimin tetikleyicileri olarak saymaktadır:

- Rekabet gücü,

- Küresel değişimler,

- Toplumsal değiş̧imler,

- Ahlak anlayışı.

Örgütsel değişimin önündeki engelleri iki kategoride ele almak mümkündür: Bireylerden kaynaklanan engeller ve örgütlerden kaynaklanan engeller. Gilley, vd. (2009: 368-369) tarafindan ortaya koyulan, örgütsel değişimin önündeki engeller Tablo 1'de yer almaktadır.

Tablo 1. Örgütsel Değişimin Önündeki Engeller

Bireylerden Kaynaklanan Engeller Ö̈rgütlerden Kaynaklanan Engeller

- Bilinmeyenden korkma,

-Zayıf liderlik/yönetim,

- Başarısızlıktan korkma,

- Değişime desteğin yetersizliği,

- Çatışmaya karşı tahammülsüzlük,

- Güvenlik, güç, statü ya da kontrol kayb1 algisı,

- Değişim için ayrılan kaynağın yetersizliği,

- Değişime karşı güdülenmeme,

- Kaynak paylaşımına yönelik örgüt içi anlaşmazlıklar,

- Akran baskısı,

- Yöneticiler ve çalışanlar arsındaki

- Değişime yönelik bilgi eksikliği, güvensizlik,

• Yönetime karşı güvensizlik,

- Düşük düzeyde değişime adanmışlık, 
- Yönlendirme ya da bilgilendirme konusunda eksiklik.
- Değişimin getirilerinin az olmas1,

- Değişime direnmenin ya da değişimde başarısızlığının yaptırımlarının olmamas1,

- Yetersiz politika ve yöntemler,

- Çatışmaya karşı tahammülsüzlük,

- Risk alanların cezalandırılmas1,

- Zayıf iletişim.

Örgüt kültürü literatüründe, kültürün değişip değişmediği, değişiyorsa bu değişimin yönetilip yönetilemediği soruları önemli yer tutmaktadır. Örgüt kültürü durağandır ve kültürün çevredeki ya da insanlardaki değiş̧ime direnmesi kültürün tanımlayıcı bir unsurudur. Aynı zamanda, kültür değişir ancak burada konu liderlerin kültürü arzu ettikleri yönde amaçlı bir biçimde değiştirip değiştiremeyeceğidir (Ehrhat vd., 2014: 295-296).

Örgüt kültürü, stratejinin uygulanması ve değişimin tamamlanmasını kolaylaştırabilir ya da zorlaştırabilir. Kültürün değişim için doğrudan hedef alınmadığı durumlar da dahil olmak üzere örgüt kültürü, örgütsel değişim çabasındaki en önemli unsurdur (Alvesson ve Sveningson, 2016: 40).

Örgüt kültürünün değişimi şu genel adımların tamamlanmasıyla gerçekleştirilebilir (Alvesson ve Sveningson, 2016: 50):

1. Örgütün durumunun değerlendirilmesi ve hedefler ile stratejik yönün belirlenmesi,

2. Mevcut kültürün analiz edilmesi ve hedeflenen kültür taslağının belirlenmesi,

3. Mevcut olanla arzulanan arasındaki boşluğun analiz edilmesi,

4. Kültürü geliştirmek için plan oluşturulması,

5. Planın uygulanması, 
6. Değişimlerin ve ilerlemeye ilişkin yeni girişimlerin ya da kültürel değişimin sürdürülebilirliğini sağlamak için alınan önlemlerin değerlendirilmesi.

\section{Araștırmanın Amacı}

Nitelikli meslek elemanlarının yetiştirilmesi ve iş piyasasına dahil edilmesi, ülkemizin kalkınmışlık düzeyi açısından önem taşımaktadır. Meslek liselerinde verilen eğitimin niteliğinin arttırılmasının önemli ayaklarından birinin de bu okullardaki örgüt kültürünün irdelenmesinin ve sürekli değişim gerektiren sektörel ihtiyaçlara ayak uydurabilmeleri bakımından bu okulların kültürel değişimlerinin ne tür engellerle karşılaştı̆̆ının tespit edilmesinin olduğu düşünülmektedir. $\mathrm{Bu}$ bağlamda, bu araştırmanın amacı meslek lisesi öğretmenlerinin örgüt kültürünün kaynaklarına ve örgüt kültürü bağlamında değişimin önündeki engellere yönelik görüşlerini incelemektir. Bu temel amaç çerçevesinde şu sorulara cevap aranmıştır:

(i) Öğretmenlere göre, örgüt kültürünün kaynakları nelerdir?

(ii) Öğretmenlere göre örgüt kültüründe öncelikli olarak değişime gidilmesi gereken alanlar nelerdir?

(iii) Öğretmenlere göre örgüt kültürünün değişiminin önündeki engeller nelerdir?

\section{YÖNTEM}

$\mathrm{Bu}$ araştırma, nitel araştırma desenlerinden olgubilim deseninde yürütülmüştür. Olgubilim, olguları derinlemesine tanıyıp kavramamıza yardımcı olacak sonuçlara ulaşabilmek için uygun zemin oluşturur (Yıldırım ve Şimşek, 2016: 69-73). Olgubilimde, çalışma grubundaki bireylerin olguya ilişkin tecrübelerinin anlamı ve yapısının ne olduğunun tespit dilmesi amaçlanmaktadır (Patton, 2002: 104). Bu çalışmada, meslekî ve teknik ortaöğretim kurumlarında çalışan öğretmenlerin görüşme sorularına verdikleri yanıtlara dayanarak öğretmenlerin örgüt kültürü ve kültür değişimine ilişkin görüşlerini ortaya koymak için olgubilim deseni kullanılmıştır. Çalışmada veriler, katılımcılarla yüz yüze bireysel görüşmeler yapılarak toplanmıştır. Verilerin toplandığı tarihlerde etik kurul izni zorunluluğu bulunmadığı için etik kurul izni alınmasına gerek duyulmamıştır.

\section{Çalışma Grubu}

Çalışma gurubunun belirlenmesinde amaçlı örnekleme yöntemlerinden ölçüt örnekleme kullanılmıştır. Ölçüt örneklemede önceden belirlenmiş ölçütleri karşılayan durumlara yönelik çalışma yürütülmektedir (Yıldırım ve Şimşek, 
2016: 122). Bu çalışmada göz önünde bulundurulan ölçüt, katılımcıların meslekî ve teknik ortaöğretim kurumunda çalışan öğretmenler olmalarıdır. $\mathrm{Bu}$ araştırmanın çalışma grubunu 2017-2018 eğitim-öğretim yılında İstanbul ilinde meslekî ve teknik Anadolu liselerinde görev yapan gönüllü 18 öğretmenden oluşmaktadır. Katılımcılara Ö1, Ö2, .. Ö18 şeklinde rumuz verilmiştir. Katılımcı görüşlerini ortaya koyan ifadeler bu rumuzlar aracılığıyla aslına uygun bir biçimde alıntılanmıştır. Tablo 2'de katılımcılara ilişkin bilgiler görülmektedir.

Tablo 2. Katılımcılara ilişkin bilgiler

\begin{tabular}{|c|c|c|c|c|c|}
\hline Katılımcı & Kidem & Cinsiyet & Branş & $\begin{array}{c}\text { Haftalık Ders } \\
\text { Yükü }\end{array}$ & $\begin{array}{c}\text { Kurumda } \\
\text { Çalışma Süresi }\end{array}$ \\
\hline Ö1 & 16 yll ve üstü & Erkek & Kültür & 16-21 saat & 16 yll ve üstü \\
\hline Ö2 & $1-5 \mathrm{y} 1 \mathrm{l}$ & Kadın & Kültür & 22-30 saat & $1-5$ y1l \\
\hline Ö3 & $11-15$ y1l & Kadın & Meslek Dersi & $16-21$ saat & $1-5 \mathrm{y} 1 \mathrm{l}$ \\
\hline Ö4 & $11-15$ y1l & Erkek & Meslek Dersi & 41 saat ve üstü & $11-15$ y1l \\
\hline Ö5 & $1-5$ yil & Kadın & Kültür & 22-30 saat & $1-5$ y1l \\
\hline Ö6 & 16 yıl ve üstü & Kadın & Kültür & 16-21 saat & 16 y1l ve üstü \\
\hline Ö7 & $1-5$ y1l & Kadın & Meslek Dersi & 41 saat ve üstü & $1-5 \mathrm{y} 11$ \\
\hline Ö8 & 16 yıl ve üstü & Kadın & Meslek Dersi & 41 saat ve üstü & $11-15$ y1l \\
\hline Ö9 & $11-15$ y1l & Kadın & Kültür & 22-30 saat & $11-15$ y1l \\
\hline Ö10 & $1-5$ y1l & Erkek & Meslek Dersi & 41 saat ve üstü & $1-5$ y1l \\
\hline Ö11 & $1-5$ y1l & Erkek & Meslek Dersi & 41 saat ve üstü & $1-5 \mathrm{y} 1 \mathrm{l}$ \\
\hline Ö12 & 16 yll ve üstü & Kadın & Meslek Dersi & 41 saat ve üstü & 16 y1l ve üstü \\
\hline Ö13 & $11-15$ y1l & Erkek & Kültür & $22-30$ saat & $11-15$ y1l \\
\hline Ö14 & 16 yll ve üstü & Kadın & Meslek Dersi & 41 saat e üstü & $6-10 \mathrm{y} 11$ \\
\hline Ö15 & $1-5$ y1l & Erkek & Meslek Dersi & 41 saat ve üstü & $1-5$ y1l \\
\hline Ö16 & $1-5 \mathrm{y} 11$ & Erkek & Kültür & 22-30 saat & $1-5 \mathrm{y} 1 \mathrm{l}$ \\
\hline Ö17 & 16 yıl ve üstü & Kadın & Kültür & $22-30$ saat & 16 y1l ve üstü \\
\hline Ö18 & $1-5$ y1l & Kadın & Meslek Dersi & 41 saat ve üstü & $1-5$ y1l \\
\hline
\end{tabular}

Tablo 2 incelendiğinde katılımcıların 8'inin 1-5 yıl arasında, 4'ünün 11-15 yıl aralığında ve 6'sının 16 yıl ve üstü meslek kıdemine sahip olduğu görülmektedir. Katılımcıların 11'i kadın, 7'si erkektir. Branş itibarıyla kültür dersi öğretmeni sayıs1 8, meslek dersi öğretmeni sayısı 10'dur. Katılımcıların 3'ünün haftalık ders yükü 16-21 saat aras1, 6'sının haftalık ders yükü 22-30 saat aras1 ve 9'unun haftalık ders yükü 41 saat ve üstündedir. Katılımcıların 9'unun aynı kurumda çalışma süresi 1-5 yıl arasında, 4'ünün aynı kurumda çalışma süresi 11-15 yıl arasında ve 4'ünün aynı kurumda çalışma süresi 16 yıl ve üstündedir.

\section{Veri Toplama Aracı}

Araştırmacılar tarafından alan yazın taraması yapılmış, açık uçlu üç ana soru ve üç sonda sorusunun yer aldığı bir görüşme formu hazırlanmıştır. Görüşme 
formuna yönelik olarak eğitim yönetimi ve denetimi alnında çalışma yürüten 3 farklı akademisyenden uzman görüşü alınmıştır. Uzman görüşü doğrultusunda ihtiyaç duyulan kavramsal düzeltmeler yapılarak form uygulamaya hazır hale getirilmiştir. Hazırlanan yarı yapılandırılmış görüşme formu kullanılarak çalışma grubu dışındaki 4 öğretmenle pilot uygulama yapılmıştır. Gerçekleştirilen pilot uygulamada soruların anlaşılırlığı açısından bir olumsuzluk bulunmadığı tespit edilmiş, görüşmelerin ortalama 30-40 dakika aralığında sürdüğü gözlemlenmiştir. Bu uygulamanın ardından, mevcut yarı yapılandırılmış görüşme formunun veri toplama aracı olarak kullanılmasına karar verilmiştir. Katılımcılara, araştırmanın amacı ve içeriğine yönelik açıklama yapılmıştır. Katılımcılara, verdikleri bilgilerin yalnızca bu bilimsel çalışmada anonim olarak kullanılacağı belirtilmiştir. Ses kaydı yapılmasının katılımcılar tarafından tedirginlikle karşılanması ve kabul görmemesinden dolayı öğretmenlerin verdiği cevaplar görüşme esnasında araştırmacı tarafından not alınmıştır. Araştırmaya gönüllü olarak katılan öğretmenlerle yüz yüze görüşme gerçekleştirilmiştir. Tüm görüşmeler, 4 - 29 Mayıs 2018 tarihleri arasında, okul dışında, öğretmenlerin boş zamanlarında gerçekleştirilmiştir. Her bir görüşme 30-40 dakika arasında sürmüştür.

\section{Verilerin Analizi}

Araştırmada elde dilen veriler nitel araştırma yöntemlerinden bağlamla ilgili olarak benzerliği tespit edilen metinleri belirli kavramlar altında bir araya getirerek anlamlı çıkarımlar yapmaya yarayan bilimsel bir veri analiz yöntemi olan içerik analizi ile incelenmiştir (Krippendorff, 2004: 18; Weber, 1990: 9; Yıldırım ve Şimşek, 2016: 242). İçerik analizi, kategoriler oluşturma ve bu kategoriler arasında bağlantılar kurarak toplanan verilerde bu kategorilerin bulunma sayısı üzerinden yapılan değerlendirmeyi içermektedir (Silverman, 2013: 811). İçerik analizinde amaç, metindeki birçok kelimenin daha az sayıda kategori altında gruplandırılmas1, tutarlılıkların ve anlamların belirlenmesine yönelik anlamlandırılmasıdır. Her bir kategoride yer alan kelimeler, ifadeler ve diğer metin bölümleri benzer anlamlar ifade eder (Patton, 2002: 453; Weber, 1990: 12).

Toplanan veriler araştırmacılar tarafından dijital ortama aktarılmış ve NVivo 11 programı ile nitel analiz gerçekleştirilmiştir. İçerik analizi esnasında, görüşmelerden elde edilen veri, araştırmacılar tarafından birbirinden bağımsız olarak dikkatli bir şekilde incelenmiş, araştırmanın amaçları göz önünde bulundurularak ortaya çıkan anlamlara göre kodlar belirlenmiştir. Veriler incelenmiş ve tespit edilen benzerlik ve farklılıklar göz önünde bulundurularak gruplandırılmıştır. Ardından, aralarında ilişki bulunan kodlar bir araya getirilmiş ve temalar oluşturulmuştur. Veri analizinin güvenirliğini temin etmek amaciyla Miles ve Huberman (1994) tarafından ortaya koyulan formül (Güvenirlik = görüş 
birliği / görüş birliği + görüş ayrıllı̆ 1 X 100) kullanılmıştır. Güvenirliğin sağlandığının göstergesi olarak $\% 70$ oranı dikkate alınmıştır (Miles ve Huberman, 1994: 64). Gerçekleştirilen güvenirlik çalışmasında araştırmacılar tarafından birbirinden bağımsız olarak yapılan iki kodlama arasındaki uyum \%88 olarak hesaplanmıştır.

\section{BULGULAR}

Araştırmanın amacı doğrultusunda ve görüşme analizleri sonucunda elde edilen veriler üç tema altında toplanmıştır. Bu temalar; 1) Örgüt kültürünün kaynakları; 2) Örgüt kültüründe öncelikli olarak değişime gidilmesi gereken alanlar; 3) Örgüt kültürü değişiminin önündeki engeller. Bu bölümde, belirlenen her bir temada yer alan kodlar ve alıntılar yer almaktadır.

\section{Örgüt Kültürünün Kaynakları}

Örgüt kültürünün kaynaklarına ilişkin öğretmen görüşlerinin analizi sonucu elde edilen bulgular Şekil 2'de sunulmuştur.

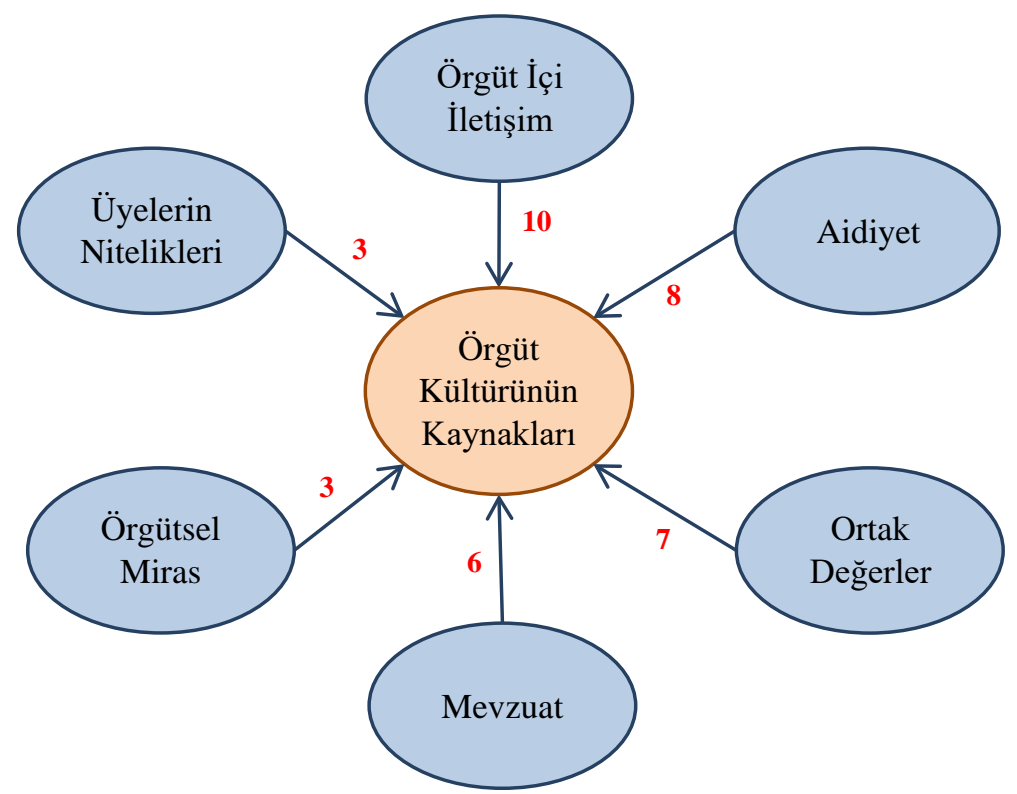

Şekil 2. Örgüt kültürünün kaynakları

Şekil 2 incelendiğinde, katılımcıların görüşlerine göre örgüt kültürünün kaynağı olarak en çok örgüt içi iletişimin ifade edildiği görülmektedir. Bunu sırasıyla aidiyet, ortak değerler, mevzuat, örgütsel miras ve örgüt üyelerinin nitelikleri izlemektedir. Katılımcıların bu temaya ilişkin öne çıkan görüşlerin bazıları aşağıda sunulmuştur. 
Ö1, iletişimin örgüt kültürü için önemini şu şekilde dile getirmektedir:

"Kültür, içinde daima bir miras ögesini tutar. $\mathrm{Bu}$ özelliği onu geçmişle bağlantısız düşünmemizi zorlaştırır. Ödülleri, etkinlikleri, uygulamaları, ayrıca öğretmenlerinin, öğrencilerinin, idarecilerinin nitelik ve dolayısıyla değerleri, kurumun iç iletişim şekli ile kurumun çevresindeki algısı bir dönemde o kurumun insanların zihinlerinde oluşan resminin ögeleridir. Bu mirasa eklenen süreç, kurumu bir arada tutan ortak değerlerin şekillendiği ve ifadesinin o kuruma özgü hale geldiği bir kaptır.”

Diğer taraftan Ö18, iletişime ilişkin şunları dile getirmektedir: "Kişiler arası iletişim ne kadar güçlü ise kurumsal başarı da o oranda artar." Ö12 de benzer bir şekilde iletişimle ilgili olarak şunları ifade etmektedir: "Okulumuz diğer okullardan ayıran şeyin çalışanlar arsındaki olumlu iletişim, saygı ve çalışma uyumu olduğunu düşünüyorum.”

Ö1, aidiyet hissinin, örgütsel mirasın ve üyelerin niteliklerinin örgüt kültürü bakımından önemini şu şekilde ifade etmektedir:

"Okula yeni gelen bir öğretmenden sıklıkla duyulan 'Biz böyle yapıyorduk' şaşkınlığı, kurumların benzer işleri ele alışlarının farklılaşabildiğini gösterir. $\mathrm{Bu}$ cümle her kurumun kendi kompozisyonunu farklı biçimlerde kurduğunu göstermenin yanında daha derin bir şeye de işaret eder. Buradaki 'biz' diğerlerinden farklı olduğunu ilan eder. $\mathrm{Bu}$ aidiyet bildiren bir kelimedir. Kültür, sürekliliğini aidiyete dayandırır. İster çocuk ister yetişkin her insan fark edilmek ister. Kurum içinde var olmak ne kadar mütevazi olsa da her birey için önemlidir. Okulumda gerek idare tarafından gerek öğretmenler tarafından bu farkındalık kazanılmıştır. Çalışanların çabaları, işleri, başarıları nedeniyle topluluk önünde varlıkları bir kez daha onaylanır. Bu gerçekten büyük resme dahil olmanızı pekiştiren, aidiyetinizi güçlendiren bir tavırdır."

Ö7, örgüte ait hissetmenin örgüt kültürünün temelinde yer aldığını şu şekilde dile getirmektedir: "Bir kurumun ya da sistemin ayakta durması, paydaşlarının kurum içinde mutluluğuna ve aidiyet duygusunun yüksek olmasına bağlı olduğunu düşünüyorum.”

Örgüt kültürünün diğer bir kaynağının ise ortak değerler olduğu tespit edilmiştir. Ö6, tüm örgüt üyelerince kabul görmüş ve ortaklaştırılmış öğelerin önemini vurgulamaktadır: "Kurum kültürü yazılı veya resmi olmayan kural, uygulama ve alışkanlıklardır. Bu noktada okuldaki herkes için ortak kurallar koyulmuş ya da herkesin fikir birliğine vardığı alışkanlıklar oluşturulmuşsa ve 
bunlar da herkes için eşit bir şekilde uygulanıyorsa orada kurum kültüründen bahsedilebilir". Ö18, ortak değerlerin önemine şu şekilde dikkat çekmektedir: "Kurum kültürü bir bütündür. Okulumuzun belli bir ilkesi, vizyonu var. Bu hedefeler doğrultusunda da gelişim planları yapılıyor. Bunlar sayesinde okulda çalışan idareci, öğretmen ve diğer personeller tarafından benimsenen değerler vasıtasıyla okulun amacına yönelik ortak duruş sergileniyor”.

Çalışmada, örgüt kültürünün mevzuat düzenlemelerinden kaynaklandığının ifade edildiği de gözlemlenmiştir. Ö2, bu konuda şöyle demektedir: "Çalıştı̆̆ım okulda kurum kültürü oluşmuştur. Yapılan iş ve işlemler mevzuat ve yönetmelik doğrultusunda genel kaidelere uygun olarak yapılmaktadır." Benzer bir şekilde Ö12, "Okulumuzdaki kurum kültürünün yazılı kurallar ve yönetmelikler belirliyor bence. Bu kural ve yönetmeliklere uygun davranışların sergilenmesi bekleniyor. Kural ve yönetmelik dışında davranış ve değerler de mevcut elbette." demektedir. Diğer taraftan Ö13 şu şekilde fikir beyan etmiştir: "Bütün öğretmenler ve diğer çalışanlar arasında çok güçlü bir uyum bulunuyor. Herkes görev ve sorumluluk alanlarını biliyor ve gereğini yerine getiriyor. Çünkü bütün işlemler yazılı olarak ortaya koyulmuş kurallar çerçevesinde gerçekleştiriliyor."

\section{Örgüt Kültüründe Öncelikli Değişime Gidilmesi Gereken Alanlar}

Örgüt kültüründe öncelikli olarak değişime gidilmesi gereken alanlara ilişkin öğretmen görüşlerinin analizi sonucu elde edilen bulgular Şekil 3'te şematik olarak sunulmuştur.

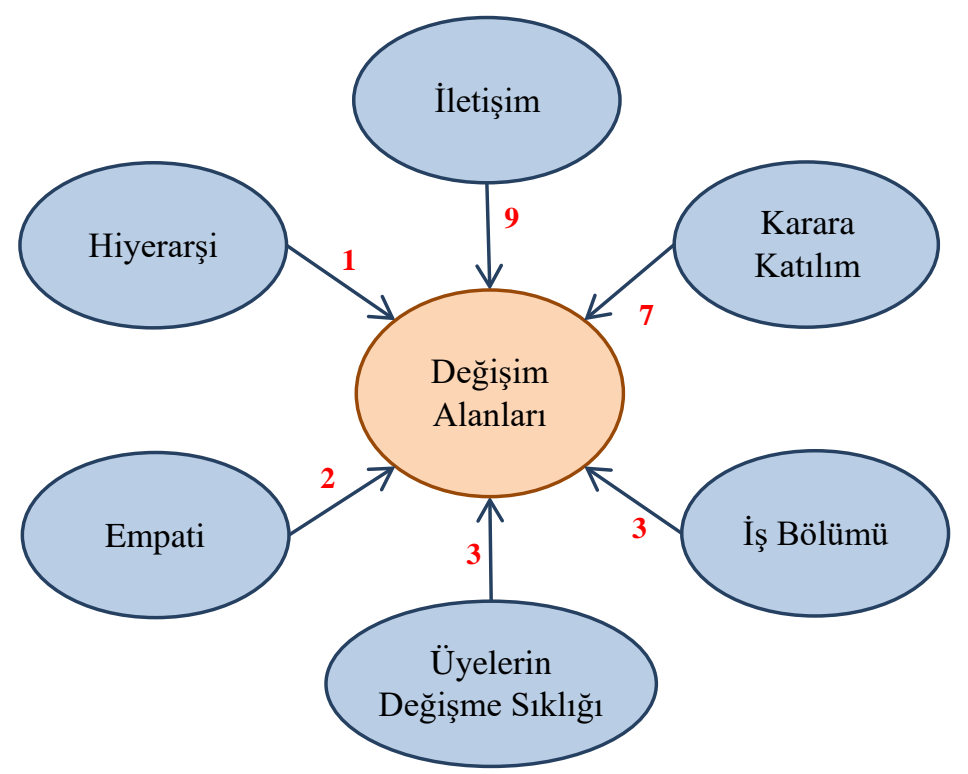

Şekil 3. Örgüt kültüründe öncelikle değişime gidilmesi gereken alanlar 
Şekil 3 incelendiğinde, katılımcıların görüşlerine göre örgüt kültürünün öncelikli müdahale gerektiren alanının iletişim olarak dile getirildiği görülmektedir. Bunu sırasıyla karara katılım, iş bölümü, üyelerin değişme sıklığı, empati ve hiyerarşi izlemektedir. Katılımcıların örgüt kültürünün öncelikli müdahale alanlarına ilişkin öne çıkan görüşlerinin bazıları aşağıda sunulmuştur.

Araştırmanın katılımcıları tarafından örgüt kültürünün öncelikli kaynağı olarak gösterilen iletişimin örgüt kültüründe müdahale edilecek öncelikli alan olarak ifade edildiği gözlemlenmiştir. Ö6, örgüt üyeleri arasındaki iletişimin önemini ve karş1lklı kabullenmenin önemini şu sözlerle ifade etmektedir:

"Kurum kültürünün oluşmasında ve sürekliliğinde kişiler arasındaki iletişim ve kabullenme duygusunun güçlü olması gerektiğini düşünüyorum. Çünkü kurumsal bir kimlik oluşturulacaksa bu hep birlikte yapılabilecek bir şey ve de sürekliliğini de sağlamak gerekir. İletişim derken eski ve yeni çalışanlar arasındaki iletişim aktarımı ve oryantasyondan bahsediyorum. Ayrıca kurum çalışanlarının iletişim yönlerinin geliştirilmesinden de bahsediyorum. İletişimi güçlendirmek adına birleştirici, bir araya getiren etkinlikler ve organizasyonlar düzenlenebilir. Veli, öğretmen ve öğrencilerin tanışabileceği toplantılar, mezuniyet törenleri, okul kuruluş yıl dönümü kutlamaları, pilav günleri gibi.”

Ö9, okul örgütünün üyelerini yalnızca öğretmenlerle sınırlamamakta, öğretmenler arasında olduğu kadar öğrenci-öğretmen ve öğrenci-öğrenci iletişiminin de önem taşıdı̆̆ını dile getirmektedir:

"İletişimi güçlendirirdim. Bunun için de iletişim koçu olurum. Bu sadece öğretmen - yönetici ilişkisi anlamında değil, öğretmen öğrenci ilişkisi ile de ilgili olur. Özellikle öğrenciler duygularını dile getiremiyor. Aylık olarak okuldaki öğretmenler arasında geziler, sohbet toplantıları yapılabilir. Öğretmenlerin öğrenciler ile ortak alanlarda buluşabilecekleri forumlar yapılabilir. Çünkü öğrenciler öğretmenleri ile ilgili düşünceleri onların verimliliğini ve okula olan bağlılıklarını arttırır. Öğretmenlerin istekleri anlatmaları noktasında sıkıntı yok ama iletişim eksikliğinden dolayı zaman zaman yanlış anlaş1lmalar yaşanabiliyor.”

Örgüt kültüründe müdahale gerektiren başlıca alanlar arasında örgüt üyelerinin karar alma süreçlerine katılmasının yer aldığg sonucuna ulaşılmıştır. Ö17, karar alma süreçlerine dahil edilen örgüt üyelerinin aidiyet hislerinin kuvvetleneceğini şu sözlerle ifade etmektedir: 
"Kurum kültürünü geliştirmek için eksikleri, gerekenleri, sorunları tüm öğretmen ve çalışanlarla tespit edip çözüm önerilerini de hep birlikte değerlendirip karar sürecine herkesi dahil ederdim. Kurum üyeleri kurumun işlerliği ile ilgili kararlara katıldıkları oranda aitlik duygusunun gelişeceğini ve kurallara daha sıkı sahip çıkacaklarını düşünüyorum.”

Ö19, karar alma sürecine katılan örgüt üyelerinin, verilen karara ilişkin sonuçların sorumluluğuna da üstleneceğini belirtmektedir: "Çalışanların karar süreçlerine daha fazla katılmasını sağlamanın önemli olduğunu düşünüyorum. Alınan kararlarda etkili olmak aynı zamanda sorumluluk almak ve sorunu sahiplenmek olacağından herkesin sorun çözmede daha aktif olmasını bekliyorum".

Ö15, "Görev tanımları ve planlama öncelikli müdahale alanım olurdu." diyerek iş bölümünün müdahale gerektiren bir unsur olduğunu dile getirirken Ö4, “Gönüllülük esaslı küçük iş değişiklikleri, rotasyon yapardım.” demektedir.

Örgüt kültürüne ilişkin müdahale gerektiren alanlar arsında örgüt üyelerinin değişim sıklığı da gösterilmektedir. Katılımcıların görüşleri incelendiğinde, örgüt üyelerinin sıklıkla değişmesinin yerleşik bir kültür tesis edilmesine engel olarak görüldüğünü söylemek mümkündür. Ö12, bu durumun önemini şu sözlerle vurgulamaktadır:

"Her sene personelde illa ki değişmeler oluyor, tayinle gelenler ya da gidenler gibi. Dolayısıyla bir kurum kültürü oluşacaksa bunun sürekliliği de sağlanmalıdır. Çalışanlar arasında bir bağlılık ve dayanışma olması gerekli, zaten kurum kültürünün de amacı bu değil mi. Biz bir şekilde eskilerle bu kısmı çözdük diye düşünüyorum. Fakat yenilere de bu kurum kültürünün aşılanması gerekiyor.”

Ö3, örgüt üyelerinin sıklıkla değişmesi durumunda örgüt kültürünün bu durumdan olumsuz etkilendiğini ifade etmektedir:

"Kurum kültürünün pozitif yönde ilerlemesi için öğretmen kadrolarının eş durumu, il içi, il dışı tayin gibi gerekçelerle sık sık değişmemesi gerekir. Çünkü okullarda sürekli sirkülasyon oluyor ve personel kendini o okula ait hissetmiyor. Takım ruhu oluşmuyor. Okullarını sık sık değiştirilmesine yönelik önlemler alınabilir. Kadrolu personelin uzun yıllar aynı kurumda çalışması teşvik edilebilir.” 
Ö15 de benzer bir şekilde şunları ifade etmektedir: "Kurum kültürünün oluşması için kurumda çok sık çalışan değişim olmaması ya da kadroda büyük değişikliklerin olmaması gerektiğini düşünüyorum."

Ö10, "Empati duygusunun zayıflı̆̆ zedelenmesine sebep oluyor. İdarecilerin öğretmen, öğretmenlerin idareci gözüyle yaklaşması gerekir.” diyerek örgüt kültürünün empatinin öncelenmesiyle daha iyi hale getirilebileceğini düşündüğünü dile getirirken Ö1, örgütün işleyişinde hiyerarşik yapıya gönderme yapan uygulamaların örgüt kültürü açısından değerlendirilerek düzenlenmesi gerektiğine ilişkin düşüncesine şu sözlerle dikkat çekmektedir:

"Kurum içi hiyerarşiye gereksiz vurgu yaparak odak noktası haline getiren, iletişimi bozarak aidiyeti zayıflatan uygulamalar da söz konusu. Öğretmen ve idareci tuvaletlerinin ayrilması gibi hiyerarşiye vurgu yapan uygulamalar bir sorunu çözmek isterken daha büyük bir soruna yol açabiliyor.”

\section{Örgüt Kültürü Değişiminin Önündeki Engeller}

Örgüt kültürü değişiminin önündeki engellere ilişskin öğretmen görüşlerinin analizi sonucu ulaşılan bulgular Şekil 4'te sunulmuştur.

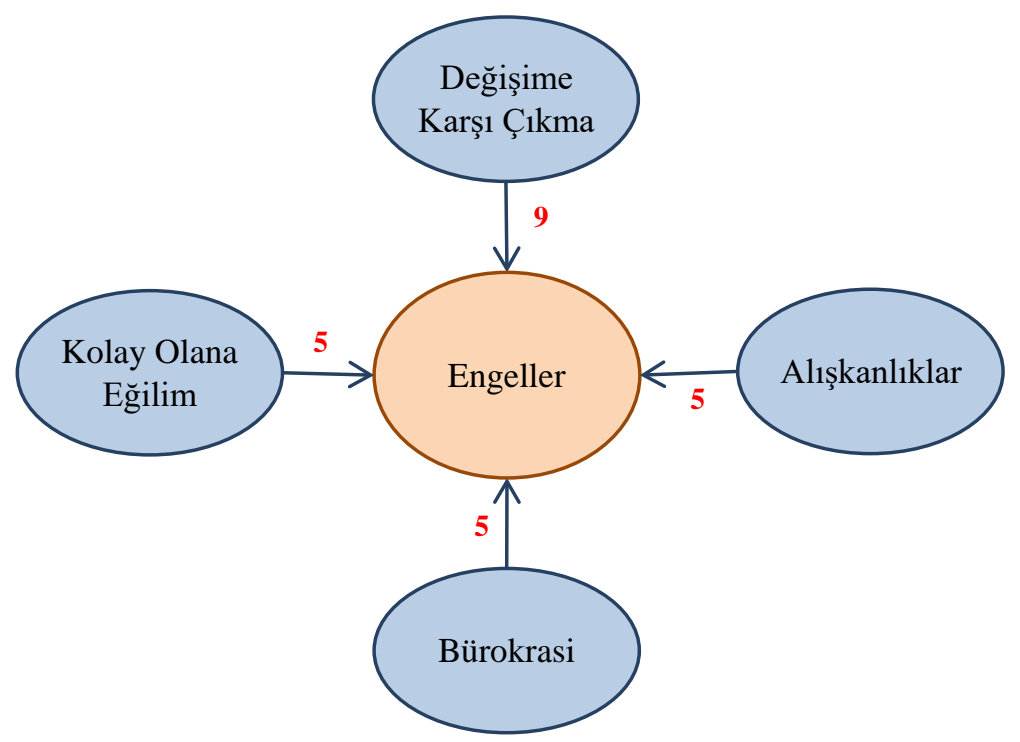

Şekil 4. Örgüt kültürü Değişiminin Önündeki Engeller 
Şekil 4'te katılımcıların görüşlerine göre örgüt kültürünün değişiminin önündeki başlıca engelin değişime karşı çıkmanın ifade edildiği görülmektedir. Bunu sırasıyla alışkanlıklar, bürokrasi ve kolay olana eğilim takip etmektedir. Katılımcıların bu temada öne çıkan görüşlerinin bazıları aşağıda sunulmuştur.

Örgüt kültürünün değişiminin önündeki engel olarak en sık örgüt üyelerinin değişime karşı çıkmasının dile getirildiği gözlemlenmiştir. Ö7 örgüt üyelerinin değişime karşı çıkmasına ilişkin şunları dile getirmiştir:

"Kurum kültürü bir alışkanlıktır ve alışkanlıkları kazanmak ve kazandırmak kolay değildir. Zaman ve emek ister. Liderlerin bu süreci dengeli ve iyi bir şekilde kontrol ve aynı zamanda idare etmesi gerekir. Kimseyi kırmadan ama aynı zamanda kimseye ödün vermeden. Direnenler olacaktır. Katılmayanlar, kabullenmek istemeyen ve reddedenler olacaktır."

Ö13, değişime karş1 çıkan örgüt üyelerine karş1 yaptırım uygulanarak bu engelin ortadan kaldırılabileceğini ifade etmektedir:

"Eski kurum kültüründen vazgeçmek istemeyen ya da başka sebeplerden dolayı buna direnen kişiler elbette olabilir. Kurumumda genel bir değişiklik çoğunluk tarafından benimsendiğinde bu tür kişiler de zamanla farkında olmadan istediğim yönde değişime uğrayacağını düşünüyorum. Bu sebeple zamana yayarım. Ancak bu zamandan sonra da çoğunluğun kabul ettiği ve kurumun kültür haline gelmiş şeylere bu kişilerin zarar verdiğini görürsem, bu kişilerin okul kültürüne ayak uydurmasını temin etmek için yasal yetkilerimi kullanarak bu yönlendirmeyi yapardım."

Araştırmanın katılımcılarının örgüt üyelerinin mevcut alışkanlıklarının örgütsel değişimin önündeki önemli diğer bir engel olduğunu ifade ettikleri gözlemlenmiştir. Ö2, örgüt alışkanlıkların örgüt kültürünün değişimine engel olacağını şu sözlerle özetlemektedir: "Alışkanlık haline gelen rutin çalışma anlayışını kırmak için çabalama, çatışmalara yol açabilir”. Bu konuda Ö16, bireylerin geçmiş yaşantılarının ve bu yaşantılardan kaynaklanan alışkanlıklarının kurum kültürünün değişiminin önünde engel olduğuna yönelik düşüncesini şu şekilde dile getirmektedir: 
"Sonuçta kurumda çalışan insanlar arasında farklılıklar bulunmaktadır. Doğup büyüdükleri şehirler farklıdır. Buna bağlı olarak, hayata dair görüşleri, yaşam şekilleri, kültürel değerleri, eğitim seviyeleri farklılık gösterebilir. Bu farkl1lıklar varken insanları ortak değerlerde birleştirmek çok meşakkatli bir süreçtir ve çok fazla emek harcamayı gerektirir."

Araştırmanın katılımcılarının örgüt kültürünün değişiminin önündeki engeller arasında bürokratik yapıyı dile getirdikleri görülmüştür. Ö3, örgüt kültürüne ilişkin hayal ettiği değişiklikleri hayata geçirmeye kalktığında bürokrasinin engel olarak karşısına çıkacağına dair düşüncesini şu şekilde ifade etmektedir:

"Büyük okullardan ziyade butik okullarda mesleki eğitimin verilmesinin kurum kültürünü de olumlu etkileyeceğini düşünüyorum. Ya da okuldaki her alan için o alandan bir müdür yardımcısının görevlendirilmesi sağlanabilir. Ama böyle bir müdahaleye Millî Eğitim Bakanlığı izin vermez diye düşünüyorum. Bir de yöneticilerin iş yüklerinin artmasından dolayı isteksiz olacaklarını tahmin ediyorum."

Benzer bir şekilde Ö12 de örgüt kültürünün değişimine ilişkin atılan adımlarda bürokrasiyi engel olarak algıladığını belirtmektedir: "Ortaya çıkan problemlerin çözümü için kurumsallığın gereği olarak yönetmelik engeli karşıma çıkartılabilir."

Araştırmada, örgüt kültürünün değişiminin önündeki engeller arasında kolay olana eğilimin yer aldığının dile getirildiği görülmüştür. Ö2, örgüt üyelerinin kendileri için kolay olarak gördükleri uygulamalara yönelerek değişime engel olabileceklerini şu şekilde dile getirmektedir: "Çalışan ve öğretmenlerin kolay olaya yönelme eğilimi, güdüleme sürecini sekteye uğratabilir.”

\section{TARTIŞMA, SONUÇ ve ÖNERILER}

Meslek lisesinde görev yapan öğretmenlerin örgüt kültürü ve değişime ilişkin algılarının incelenmesinin hedeflendiği bu çalışma, 2017-2018 eğitim-öğretim yılında gerçekleştirilmiştir. Nitel bir çalışma olan bu araştırmanın çalışma grubunu İstanbul ilinde meslekî ve teknik Anadolu liselerinde görev yapan toplam 18 öğretmen oluşturmuştur. Araştırma sonuçları şu temalara göre gruplandırılmıştır: 1) Örgüt kültürünün kaynakları; 2) Örgüt kültüründe öncelikli 
olarak değişime gidilmesi gereken alanlar; 3) Örgüt kültürü değişiminin önündeki engeller.

Araştırmada, örgüt kültürünün örgüt içi iletişim, aidiyet, ortak değerler, mevzuat, örgütsel miras ve örgüt üyelerinin niteliklerinden kaynaklandı̆̆ 1 yönünde sonuçlara ulaşılmış̧ır. Kültürün bütüncül ve bireylere indirgenmesi mümkün olmayan bir olgu olduğu, çok sayıda bireyin bir arada olmasını gerektirdiği; gelişen bir olgu olduğu ve gelenekler vasıtasıyla başkalarına aktarıldı̆̆ı; sosyal olarak inşa edilen bir olgu olduğu, çeşitli gruplara aidiyeti bulunan kişiler tarafından paylaşıldı ğı; farklı bireylerden oluşan grupların farklı kültürler geliştirdikleri; düşünüş şekli, fikirler ve değerleri ifade ettiği bilinmektedir (Alvesson ve Sveningson, 2016: 41). Örgüt kültürünün ise örgütün üyelerinin bireysel olarak tecrübeleri, inançları, ideolojileri ve değerlerine indirgenemeyen, örgüt üyelerinin örgüt dışındaki insanlarla olduğu kadar kendi aralarındaki etkileşimi de kontrol eden, örgüt içerisinde paylaşılan değerleri ve normları ifade ettiği de bilinmektedir (Ehrhatvd, 2014: 2; Jones, 2013: 201).

Her kültürün güçlü ve zayıf yönleri vardır. Takım çalışması, iletişim, güven ve ait hissetme, örgüt kültürünün güçlü yönlerini oluşturur (Groysberg vd., 2018: 7). Shahid ve Zain (2018: 2), çalışanların örgüte karşı olumlu hisler geliştirmeleri ve örgütsel aidiyeti yaşamalarının, bir topluluğun parçası olma ihtiyaçlarını doyurmalarını da sağladığını vurgulamaktadır. Benzer bir biçimde Victorino vd., (2018: 785), ait olma ve kabul görmenin iş doyumunun birkaç öncülünden biri olduğunu ifade etmektedir.

Jones (2013: 212), örgüt kültürünün, mülkiyet hakk1 sistemi, örgüt yap1s1, örgütsel ahlak ve örgütteki bireylerin özellikleri olmak üzere dört kaynă̆ 1 bulunduğunu ifade etmektedir. Bu çalışmayla örgüt kültürünün örgüt içi iletişim biçimleri, aidiyet hissetme, paylaşllan değerler, mevzuat düzenlemeleri, üyeler arasında aktarıla gelen örgütsel miras ve örgüt üyelerinin niteliklerinin bileşiminden ortaya çıktığı yönünde ulaşılan sonuçların literatürde yer alan çalışmalarla örtüştüğünü dile getirmek mümkündür.

$\mathrm{Bu}$ araştırmada, örgüt kültürünün geliştirilmesi gereken alanlarının iletişim, örgüt üyelerinin karar alma süreçlerine katılımının teşvik edilmesi, örgüt üyeleri arasında iş bölümünün sağlıklı bir biçimde gerçekleştirilmesi, örgüt üyelerinin değişimindeki sıklık düzeyi, örgüt üyelerinin empati kurma becerileri ve örgütün hiyerarşik yapısına ilişkin durumlar olduğunun dile getirildiği tespit edilmiştir. 
Groves (2016: 8), örgüt liderlerinin örgüt içi iletişimi geliştirmenin yollarını aramasının önemine dikkat çekmektedir. Diğer taraftan Silla vd. (2017: 121), yöneticilerin, çalışanlara özerklik imkanı sağlayan iletişim politikalarını ve uygulamalarını desteklemesinin taşıdığı öneme vurgu yapmaktadır. Gordon'a (2017: 64) göre hem sözel hem de sembolik iletişimi kapsayan bir örgütsel kültür oluşturmak örgütsel hedeflere ilerlemenin yollarından biridir. Arditi vd. (2017: 137) örgüt kültürü ve iletişim arasındaki ilişkiyi vurgulamaktadır. Onlara göre örgütsel kültür, karar verme yaklaşımını, iletişimin kalitesini ve iş ilişkilerini doğrudan etkiler. İletişim, otonomi, iş yükü dağılımı, finansal kaynakların dağıtımı, çalışanların davranışları gibi birçok değişkeni etkileyen bir unsur olan örgütün hiyerarşik yapısı da örgüt kültüründen yoğun bir şekilde etkilenmektedir (Caliskan ve Zhu, 2020: 33; Lee vd., 2016: 1).

Örgüt üyeleri, örgüt kültürünün çizdiği sınırlar içerisinde kalmak kaydıyla karar alma süreçlerine dahil olabilirler (Agarwal vd., 2020: 1175). Örgütte kararları kimin aldığına bağlı olarak örgütün merkeziyetçi bir yapıya sahip olup olmadığı anlaşılabilmektedir. Merkeziyetçi yapıdaki örgütlerde karar verme yetkisi belirli bir grubun ya da kişinin elindedir (Ling vd., 2020: 715). Bireyler çoğunlukla geçmiş tecrübelerine ya da önsezilerine dayalı olarak kararlar verirler. Ancak, bu şekilde verilen kararlar her durumda işe yaramayabilir. Dolayısıyla, örgüt bağlamında ortak akıl işe koşulmadan verilen kararlar, örgütün zarar görmesine yol açma ihtimali taşır (Hahsmi ve Siddiqui, 2020: 160). Bu açıdan ele alındığında, karar verme süreçlerine örgüt üyelerinin dahil edilmesi, aynı zamanda örgüt üyelerinin örgütün işleyişine ilişkin geribildirim sağlamasını da beraberinde getirmektedir (Ling vd., 2020: 728).

Örgüt kültüründen etkilenen unsurlar arasında iş bölümünün yanında örgüt üyelerinin değişme sıklığı da yer almaktadır. Örgüt üyelerinin değişim sıklığı, yeni işe alım yapılmasını zorunlu kıldığı gibi örgüte yeni dahil olanların mevcut kültüre uyum sağlaması ya da gerekli becerilerin edinimi için zaman gerektirmesi bakımından hem maddi olarak hem de zaman olarak örgüte fazladan yük getirmektedir (Iqbal vd., 2017: 1-2; Kossek vd., 2015: 155). Dolayısıyla, örgüt üyelerinin sık değişmesi, çalışanların seçimi ve yetiştirilmesi konusunda yapılan yatırımların zayi edilmesi anlamına gelmektedir. Ek olarak, örgüt üyelerinin değişim sıklığı, yönetsel açıdan planlama yapmayı zora sokmaktadır. Örgütün insan sermayesini oluşturan üyelerinin değişim hızı, örgütün etkililiğini, verimliliğini ve genel performansını doğrudan etkileyen bir unsurdur (Kaya ve Abdioğlu, 2010). 
Empati, örgüt üyelerini olduğu kadar örgütün hizmet sunduğu bireyleri de kapsayacak biçimde adil bir etkileşim kurulmasını sağlar. Yöneticilerin ihtiyaç duyulan durumlarda ihtiyaç duyulan düzeyde empati kurabilme becerisine sahip olmaları beklenmektedir (Dolamore, 2019: 1; Oplatka, 2017: 96). Her ne kadar duygusal becerilere dayalı olmasından dolayı empati kurmanın geleneksel karar alma mekanizmaları, politikalar ve mevzuat düzenlemeleriyle şekillendirilen rasyonel karar verme süreçlerinin yerini alma ihtimalinin olumsuz sonuçlar ortaya çıkartma potansiyeli taşıdığı öne sürülse de başkalarının duygularına odaklanmak, gerçeklerin dengeli bir şekilde değerlendirilmesi için bir engel oluşturmamaktadır (Edlins, 2019: 5). Empati kurmanın örgüt kültürünün doğal bir parçası haline gelmesi, duygusal geri çekilmelerin farkına daha kolay varılması ve böylelikle örgüt üyelerinin görüşlerinin örgütsel süreçlere daha sağlıklı bir şekilde yansıtılması şeklinde getiri sağlamaktadır. Örgüt üyelerinin birbirleriyle empati kurduğu bir örgüt kültürü, üyelerin katkılarının diğer üyeler tarafından daha çok farkına varıldığının bilinmesini sağlar. Böylelikle örgütsel bağlll1k artar ve hem örgütle hem de liderlerle duygusal bir bağ kurulmuş olur. Sonuç olarak empati, iş tatmini ve motivasyonunun da artmasını sağlayabilir (Tzouramani, 2017: 202).

Örgüt kültürünün değişiminin önündeki engellerin örgüt üyelerinin değişime karşı çıkması, örgüt üyelerinin alışkanlıklarından vazgeçmeme eğiliminde olması, bürokratik işleyişten kaynaklanacak olası sorunlar ve örgüt üyelerinin kolay olan uygulamalara eğilim göstererek değişime direnç göstermesi olduğu sonucuna ulaşı1mıştır. Alan yazında, örgütsel değişimin önündeki engellerin iki kategoride ele alındığı görülmektedir: örgütlerden kaynaklanan engeller ve örgüt üyelerinden kaynaklanan engeller. Gilley vd. (2009: 368-369), zayıf bir liderlik, değişime sağlanan desteğin yetersiz oluşu, değişime ayrılan kaynakların yetersiz oluşu ve örgüt içi kaynak paylaşımından kaynaklanan anlaşmazlıklar, yönetici ve örgüt üyeleri arasındaki güvensizlik, değişime adanmışlık düzeyindeki düşüklük, değişime direnmenin herhangi bir yaptırımla karşılaşmaması, risk alan örgüt üyelerinin cezalandırılması ve iletişimin zayıf olmasını örgütlerden kaynaklanan engeller olarak sinıflandırırken örgüt üyelerinin bilinmeyenden korkması, üyelerin başarısızlıktan korkması, örgüt üyelerinin çatışmaya karşı tahammülsüz oluşu, üyelerin güçlerini, statülerini ya da sahip oldukları kontrol yetkilerini kaybedeceklerine yönelik algıları, değişime karşı güdülenmeme, diğer örgüt üyelerinin oluşturduğu akran baskısı, değişime ilişkin bilgi eksikliği, örgüt yönetimine karşı güvensizlik ve yönlendirme ya da bilgilendirme konusunda 
eksikliği örgüt üyelerinden kaynaklanan engeller olarak ifade etmektedir. Bunların yanında Özdemir vd. (2016: 295), mevcut kurum kültürünü, çalışanların değişime yönelik olumsuz algılarını ve çalışanların değişime yönelik yeterince bilgilendirilmemesini okul bağlamında değişimin önündeki engeller olarak göstermektedir. Bu çalışmada elde edilen örgüt üyelerinin karar alma süreçlerine katılımının teşvik edilmesi, örgüt üyeleri arasında iş bölümünün sağlıklı bir biçimde gerçekleştirilmesi, örgüt üyelerinin değişimindeki sıklık düzeyi, örgütün hiyerarşik yapısına ilişkin durumlar ve bürokratik işleyişten kaynaklanması olası sorunların örgütlerden kaynaklanan; örgüt üyelerinin empati kurma becerileri, örgüt üyelerinin değişime karşı çıkması, örgüt üyelerinin alışkanlıklarından vazgeçmeme eğiliminde olması, örgüt üyelerinin kolay olan uygulamalara eğilim göstererek değişime direnç göstermesinin ise örgüt üyelerinden kaynaklanan sorunlar arasında yer aldığı değerlendirilebilir.

Araştırmada elde edilen sonuçlar 1şığında şu öneriler getirilebilir:

1. Örgüt kültürü açısından örgüt içi iletişime en üst düzeyde önem atfedildiği ve iletişimin örgüt kültürünün değişiminde en fazla önem taşıyan değişkenlerden biri olduğu tespit edilmiştir. Buna göre, örgüt üyeleri arasında iletişimin güçlendirilmesini temin etmek için düzenli olarak seminerler düzenlenebilir.

2. Örgüt üyelerinin örgüte aidiyet hissetmesini sağlamak üzere sosyal etkinlikler ve okul ortamı dışında gerçekleştirilecek faaliyetler düzenlenmesi amacıyla okul yönetimlerine bütçe verilebilir.

3. Örgüt içerisinde paylaşılan ortak değerlerin ve örgütsel mirasın örgüte yeni katılan, örgütün yeni nesli olanlara aktarılmasını sağlamak amacıyla yeni katılımcılara yönelik oryantasyon çalışmaları yapılabilir, uyum süreci tamamlanana kadar örgütün eski üyelerinin yeni üyelere mentorluk yapmasına yönelik düzenlemeler yapılabilir.

4. Örgüt kültürünün sağlıklı hale getirilmesi için örgüt üyelerinin karara katılmalarının teşvik edilmesi gerektiği yönünde bir sonuca ulaşılmıştır. Buna göre, zümre kurulları ve şube öğretmenler kurullarına daha fazla yetki verilerek okul karar alma mekanizmasında öğretmenlerin daha fazla yer alması sağlanabilir, öğretmen liderliği okul yöneticilerince teşvik edilebilir, öğretmen liderler okul yöneticileri tarafindan rakip olarak algılanmamasının önüne geçilerek örgüt kültürünün destek unsurları olarak algılanmasını sağlayacak biçimde okul yöneticisi yetiştirme programları düzenlenebilir.

5. Örgüt üyelerinin iş bölümünün net bir şekilde yapılarak tüm üyelere ilan edilebilir. 
6. Örgüt üyelerinin değişimindeki sıklığın örgüt kültürüne olumsuz etki ettiği fikri ön plana çıkmıştır. Öğretmenler için üç yıl yöneticiler için dört yıl olan okullarda asgari çalışma süresine yönelik düzenlemenin bu açıdan yerinde olduğu düşünülmektedir. Ancak öğretmen değişiminin çok sık yaşandığı okullar için bu sürelerin çeşitlilik gösterecek biçimde düzenlenebilir.

7. Öğretmenlere yönelik empati kurma becerilerini geliştirmeye yönelik bilinçlendirme çalışmaları yalnızca hizmet içi eğitimlerle değil, hizmet öncesi eğitimlerle de gerçekleştirilebilir.

8. Çalışmada, değişime karşı çıkma, örgüt üyelerinin alışkanlıkları ve örgüt üyelerinin kolay olan uygulamayı tercih etme eğiliminde olmasının en sık dile getirilen örgüt kültürünün değişiminin önündeki engeller olduğu tespit edilmiştir. Buna göre, örgüt kültüründe gerçekleştirilmesi hedeflenen değişimlerin örgüt üyelerine doğru ve yeterli biçimde anlatılmasına ihtiyaç vardır. Bu noktada, okul yöneticilerinin liderlik kabiliyetleri ön plana çıkmaktadır. Dolayısıyla, okul yöneticilerinin liderlik becerilerine sahip vizyoner kişiler olarak yetiştirilmesinin yanında okul yöneticisi belirleme süreçleri bu gerçekler göz önünde bulundurularak şekillendirilebilir.

\section{KAYNAKÇA}

Agarwal, N., Bansal, R. and Fulzele, R. (2020). Review on organizational culture. Journal of Critical Reviews, 7(10), 1175-1179. https://doi.org/10.31838/jcr.07.10.231/

Alvesson, M. and Sveningsson, S. (2016). Changing organizational culture: Culture change work in progress. Routledge.

Alvesson, M. (2002). Understanding organizational culture. Sage Publications.

Arditi, D., Nayak and S., Damci, A. (2017). Effect of organizational culture on delay in construction. International Journal of Project Management, 35, 136-147. https://doi.org/10.1016/j.ijproman.2016.10.018

Burke, W. W. (2014). Organizational change. İçerisinde B. Schneider ve K. M. Barbera (Eds.), The Oxford handbook of organizational climate and culture (ss. 457-483). Oxford University Press.

Caliskan, A. and Zhu, C. (2020). Organizational culture and educational innovations in Turkish higher education: Perceptions and reactions of 
students. Educational Sciences: Theory and Practice, 20(1), 20 - 39. https://doi.org/10.12738/jestp.2020.1.003/

Dolamore, S. (2019). Detecting empathy in public organizations: Creating a more relational public administration. Administrative Theory \& Praxis. https://doi.org/10.1080/10841806.2019.1700458/

Ehrhart, M., Schneider, B. and Macey, W. (2014). Organizational climate and culture: An introduction to theory, research, and practice. Routledge.

Edlins, M. (2019). Developing a model of empathy for public administration. Administrative Theory \& Praxis. https://doi.org/10.1080/10841806.2019.1700459/

Gilley, A., Gilley, J. W., Quatro, S. A. and Dixon, P. (2009). The praeger handbook of human resource management. Greenwood Publishing Group, Westport.

Gilley, J. W., Quatro, S. A., Hoekstra, E., Whittle, D. D. and Maycunich, A. (2001). The manager as change agent: A practical guide to developing high-performance people and organizations. Perseus Publishing, Cambridge.

Gordon, G. (2017). Leadership through trust: Leveraging performance and spanning cultural boundaries. Palgrave Macmillan, Cham.

Groves, C. (2016). Educational leadership characteristics of rural high school principals and graduation rates [Yayınlanmamıs doktora tezi]. Walden Üniversitesi.

Groysberg, B., Price, J. and Cheng, Y. J. (2018). The leader's guide to corporate culture: How to manage the eight critical elements of organizational life. Harward Business Review, January-February, 2-15.

Hahsmi, K. A. and Siddiqui, D. A. (2020). Antecedents of employees' entrepreneurial orientation: The role of organizational culture and enabling environment. Business and Economic Research, 10(3), 146-180. https://doi.org/10.2139/ssrn.3681265/ 
Hatch, M. J. and Schultz, M. (2007). Relations between organizational culture, identity and image. European Journal of Marketing, 31(5/6), 356-365.

Hofstede, G., Hofstede, G. J. and Minkov, M. (2010). Cultures and organizations: Software of the mind. McGraw Hill.

Indacochea, M. M. M., Concepción, R. R. F. and Lorenzo, A. F. (2018). Management of organizational culture in the public institutions of Ecuador educational sector. Quality Innovation Prosperity, 22(1), 44-57. https://doi.org/10.12776/qip.v1i1.1044/

Iqbal, S., Guohao L. and Akhtar, S. (2017). Effects of job organizational culture, benefits, salary on job satisfaction ultimately affecting employee retention. Review of Public Administration Management, 5(3), 1-7. https://doi.org/10.4172/2315-7844.1000229/

Jones, G. R. (2013). Organizational theory, design, and change. Pearson, Boston.

Kaya, H. ve Abdioğlu, H. (2010). Çalışanların örgütten ayrılma eğilimleri üzerine bir araştırma. Amme Iddaresi Dergisi, 43, 129-165.

Kimonen, E., Nevalainen, R. and Schoen, L. T. (2017). Active learning for educational change: Finnish students and teachers as active learners. İçerisinde E. Kimonenve R. Nevalainen (Eds.). Reforming teaching and teacher education: Bright prospects for active schools (ss. 225-252). Sense Publishers, Rotterdam.

Kossek, E. E., Ollier-Malaterre, A., Lee, M. D., Pichler, S. and Hall, D. T. (2015). Line managers' rationales for professionals' reduced-load work in embracing and ambivalent organizations. Human Resource Management, 55(1), 143-171. https://doi.org/10.1002/hrm.21722/

Krippendorff, K. (2004). Content analysis: An introduction to its methodology. Sage Publications, California.

Lee, M. C. C., Idris, M. A. and Delfabbro, P. H. (2017). The linkages between hierarchical culture and empowering leadership and their effects on employees' work engagement: Work meaningfulness as a mediator. International Journal of Stress Management, 24(4), 392-415. https://doi.org/10.1037/str0000043/ 
Ling, Y., López-Fernández, M. C., Serrano-Bedia, A. M. and Kellermanns, F. W. (2020). Organizational culture and entrepreneurial orientation: examination through a new conceptualization lens. International Entrepreneurship and Management Journal, 16, 709-737. https://doi.org/10.1007/s11365-019-00600-w/

MacLean, T., Litzky, B. E. and Holderness, D. K. (2015). When organizations don't walk their talk: A cross-level examination of how decoupling formal ethics programs affects organizational members. Journal of Business Ethics,128, 351-368. https://doi.org/10.1007/s10551-014-2103-1

Miles, M. B. and Huberman, M. A. (1994). An expanded sourcebook qualitative data analysis. Sage Publications.

Oplatka, I. (2017). Empathy regulation among Israeli school principals: Expression and suppression of major emotions in educational leadership. Journal of School Leadership, 27(1), 94-118. https://doi.org/10.1177/105268461702700104/

Özdemir, T. Y., Karaköse, T., Uygun, H. ve Yirci, R. (2016). Educational employees' perceptions regarding changes in educational organizations. Revista de Cercetaresi Interventie Sociala, 53, 288-303.

Patton, M. Q. (2002). Qualitative research \& evaluation methods. Sage Publications.

Reisyan, G. D. (2016). Neuro-Organizational culture: A new approach to understanding human behavior and interaction in the workplace. Springer, Cham.

Robles, R. S. and Nuqui, A. V. (2015). Differential analysis of organizational culture of LCUP: Implications for enhancing management operations. International Journal of Advances in Management and Economics, 4(2), 77-86.

Schein, E. H. (2010). Organizational culture and leadership. Jossey-Bass.

Schein, E. H. (2011). The handbook of organizational culture and climate. İçerisinde N. M. Ashkanasy, C. P. M. Wilderom ve M. F. Peterson (Eds.), 
The handbook of organizational culture and climate (ss. xi-xiii). Sage Publications.

Scholz, C. (1987). Corporate culture and strategy-The problem of strategic fit. Long Range Planning, 20(4), 78-87. https://doi.org/10.1016/0024$\underline{6301(87) 90158-0}$

Shahid, S. and Zain, Z. (2018). Propensity of demographic factors on affective organizational commitment: An empirical study. Merit Research Journal of Business and Management, 6(1), 1-11.

Shin, Y. and Eom, C. (2014). Team proactivity as a linking mechanism between team creative efficacy, transformational leadership, and risk-taking norms and team creative performance. The Journal of Creative Behavior, 48(2), 89-114. https://doi.org/10.1002/jocb.42

Silla, I., Navajas, J. and Koves, G. K. (2017). Organizational culture and a safetyconscious work environment: The mediating role of employee communication satisfaction. Journal of Safety Research, 61, 121-127. https://doi.org/10.1016/j.jsr.2017.02.005

Silverman, D. (2013). Doing qualitative research. Sage Publications, Londra.

Tzouramani, E. (2017). Leadership and empathy. İçerisinde J. Marques ve S. Dhiman (Eds.), Leadership today (ss. 197-216). Cham, Springer.

Victorino, C., Nylund-Gibson, K. and Conley, S. (2018). Prosocial behavior in the professoriate: A multi-level analysis of pretenured faculty collegiality and job satisfaction. International Journal of Educational Management, 32(5), 783-798. https://doi.org/10.1108/IJEM-09-2017-0258

Weber, R. P. (1990). Basic content analysis. Sage Publications, California.

Yıldırım, A. ve Şimşek, H. (2016). Sosyal bilimlerde nitel araştırma yöntemleri. Seçkin Yayıncılık. 